\title{
Compact city and traditional housing areas for urban sustainability: a case study - Bursa, Turkey
}

\author{
A. Çahantimur ${ }^{1}$, R. Beceren Öztürk ${ }^{1} \&$ S. Sevgi ${ }^{2}$ \\ ${ }^{1}$ Faculty of Architecture, Uludağ University, Turkey \\ ${ }^{2}$ Faculty of Architecture and Design, Bursa Orhangazi University, Turkey
}

\begin{abstract}
There is a continual need for dwellings through which people can integrate their own values, form social links, and become anchored in a positive way. To meet this vital need, sustainability should be a core dimension of housing quality and be central to the development process as a whole. On the other hand, cities clearly appear to be the most important location for action to help the goals of the sustainable development. In this context, the purpose of this paper is to highlight the potential of historic cities and their traditional housing areas to achieve urban sustainability, in the context of compact city form. It consists of four sections with a brief introduction on the critical role of cities for sustainability. The first section highlights the importance of traditional housing areas for urban sustainability. The second section covers an evaluation of the suitability of the compact city form for historic neighbourhoods, through empirical studies undertaken in Bursa. The theoretical approach is based on the transactional perspective, which considers home and home environments as a transactional whole that defines and is defined by a range of cultural, social and psychological factors. Observational and ethnographic research methods are used together with the surveys applied in a valuable traditional neighbourhood in the city of Bursa, one of the most important historic cities of a developing country, Turkey. The paper concludes with the findings of the case study to offer some proposals for policy principles of sustainable urban development in historic cities.

Keywords: sustainability, compact city, traditional housing.
\end{abstract}




\section{Introduction}

The city is more than just a physical entity, more than a place where people live and work. As many researchers state, the city is a work of imagination, a metaphor, a symbol - and cities are like documents of cultural and historical value, composed by different elements from changing periods and varied political flavours $[1,2]$. However the globalization process has brought about a fundamental social, cultural and economic transformation, which have been experienced in cities. Especially historic cities where past and present penetrate each other giving witness to the past, and people are made participants in the whole by the spaces and places of the city which are affected by these transformation processes very heavily. They are influenced by population growth and rapid urbanization. The rising demands for more housing and emergence of new housing areas, whether formal or informal, change the character of the cities, especially traditional housing environments. At this point, the importance of sustainable urban development, which has to be understood as an action balancing the present with the future, but also with the past, clearly appears. However, the sustainable city is not a new phenomenon. Historic towns and cities around the world existed for any length of time because they were able to develop and maintain a continually rebalancing relationship among their internal, social and economic activities and externally with their natural and agricultural landscape [3].

In this context, the aim of this study is to investigate the opportunities of sustainable urban development of historic cities as they could be able to maintain in the past, but with today's conditions and life styles. The main idea of the paper is that the compact city, which is one of the urban forms for sustainable development of cities, is the most appropriate one for sustainability of historic cities. By the opportunities of this urban form it would be possible to accommodate substantial growth in the number of households without changing the original character of historic cities and also to recreate vital and viable city centres. The paper envisions sustainability of historic cities as closely bounded up with the identification of the local and cultural values they own that could be best achieved by compact city form. On the other hand, it is proposed that, the acceptability of this urban form to urban residents is one of the most important topics that have to be emphasized as an issue of social equity and choice together with the environmental criteria of sustainability. If it is not taken into consideration, those who can, will leave the city, and only the most disadvantaged will be left. This will cause a scenario, which is clearly unsustainable.

In order to discuss this proposal two empirical studies undertaken in the same environment at different times are compared by means of the changes in the opinions of the residents. The aim is to understand the reasons for the changes in the ratio of acceptability of the compact city form and if the changes caused by the urbanization process are effective or not. The case study area is a traditional neighbourhood of a valuable historic city in Turkey - Bursa. Before the presentation of the empirical study, the way we handle the relationships of the main concepts; sustainable urban development, historic city and compact city form will be explained in the following section. 


\section{Sustainability of historic cities and compact city form}

The most common definition of sustainable development is "development which meets the needs of the present without compromising the ability of future generations to meet their own needs and aspirations" (WCED, 1987); a more holistic definition of sustainability made in the 20th UIA Congress in 1999 is "a local, informed, participatory, balance-seeking process, operating within an equitable ecological region, exporting no problems beyond its territory or into the future"; and the definition of sustainable development made in the Forum for the Future (2000), is "a dynamic process which enables all people to realize their potential, and to improve their quality of life, in ways which simultaneously protect and enhance the Earth's life support systems" all show that these concepts are closely related to the concept of "human development" which is defined as "a process of enlarging people's choices" and which have the goals of "leading a long and healthy life, acquiring knowledge and having access to resources needed for a decent standard of living". Today, the authorities have come to recognize the importance of participatory and integrated approaches to the incremental implementation of sustainability. Also, local governments have found that it is necessary to not only take it in environmental terms, but also in social, economic, psychological and cultural terms, and their interrelations.

With such a large proportion of the world population, the concentration of environmental problems, and consumption of resources, cities play a pivotal role in bringing people together as a focus of social and economic activity. If successful policies and practical solutions can be found for the sustainable development of the cities, then the benefits will be great $[4,5]$. As supported with this paper, the idea of creating sustainable cities through centralisation and containment, which is named as a compact city, rather than dispersal and low-density development, is one of the sustainable urban form approaches seen in the world literature as well as practical studies. As Urbed argues, "Policies to attract people back to cities have the potential to kill three birds with one stone. They could reduce the loss of the countryside and promote more sustainable patterns of development, while at the same time addressing the root cause of urban decline by making the inner city into somewhere which people no longer wish to escape" [6, p. 15]. Heath also thinks that, the benefits of concentrating residential development within existing urban areas and the positive impacts upon the quality and vitality of these places are widely recognised, notably in the European Communities' Green Paper on the Urban Environment [7].

Breheny [5] provides an apt summary of the "compact city" as a high density, mixed-use city, where growth is encouraged within the boundaries of the existing urban areas, but with no development beyond its periphery. On the other hand, it has been suggested that a sustainable city "must be of a form and scale appropriate to walking, cycling and efficient public transport, and with a compactness that encourages social interaction" [8]. There is an important topic as Haughton and Hunter [9] pointed out - the sustainable city is not rooted in an idealised version of past settlements, nor is it one given to a radical casting-off from its own particular cultural, economic and physical identity in the name of the latest passing 
fad for urban change. At this point, the importance of historic cities for the sustainable city debate in the context of compact city form comes to the scene. As Jenks et al. [10] state, the vision of the compact city has been dominated by the model of the densely developed core of many historic European cities. Those from outside see them, often, as ideal places to live and experience the vitality and variety of urban life. However, in today's world, tensions between the demands for both development and conservation in historic cities have given rise to a growing recognition that they cannot reproduce themselves without forms of intervention, regulation and management of the physical and social fabric upon which their localness, specificity and economic success is predicated. As Urry (cited in Strange $[11,12]$ ) states, in an increasingly competitive global market where spatial and temporal barriers are diminishing, the specification of place its character, history, buildings, culture and distinctiveness - become more important. These developments have brought into focus the extent to which sustainable development policies are capable of resolving some of these conflicts.

The investigations point out that the city, whether historic or not, and whether compact or not, is a holistic system and the relationships between the parts are complex. The need for more scientific and objective knowledge has led to measurement and monitoring at the local scale and the strategic level. Research is especially needed to test the claims about the sustainability of the historic cities in the context of a compact city and to test the social acceptability of the concept. The empirical study made in the context of this paper, tried to test the social acceptability of the compact city in a historic city. The study and its details are briefly explained in the following section.

\section{Case study}

The main aim of the case study is to evaluate the acceptance of the compact city form by the urban residents living in a traditional housing area of a historic city, Bursa. Two empirical studies structured with similar conceptual frameworks were undertaken in the case study area in different years in order to find out the changes in the opinion of the residents. The first empirical study was undertaken in the scope of the Ph.D. Thesis of the first author, A. I. Çahantimur, entitled "A SocioCultural Approach for Sustainable Urban Development, A Case Study for Bursa" in Istanbul Technical University, Institute of Science and Technology, Department of Architecture, in 2007. The second empirical study was undertaken in the scope of a scientific research project carried out by the first author within the collaboration of Uludağ University and Bursa Metropolitan Municipality entitled "A Proposal of Site Management Plan for Hisar, Osmangazi/Bursa".

The reason for a housing environment to be selected for the case study is that "home" is central to human well-being in every part of the world. What's more, as Altman claims, contemporary and future centrifugal and centripetal worldwide trends ultimately affect the physical, psychological and social survival of ordinary people in terms of families and friends, homes and residences, proximate neighbours and community, and their everyday work and means of livelihood. 
Then, the challenge is to develop housing systems and approaches to housing that reflect the dynamics of contemporary society where transactions between people and the residential environment are forever evolving [13]. Thus, it can be said that the aim of this study, which is to understand the reasons of the changes in the ratio of acceptability of the compact city form and if the changes caused by the urbanization process are effective or not, is very meaningful. The outcomes will help to determine the ways of making people conscious about urban sustainability. Development alternatives of the urban form, especially the form of traditional housing environments for the achievement of urban sustainability in historic cities will be discussed. Also it will give clues about people's thoughts of sustainability studies. The data obtained can be the pioneer for developing sustainability policies in historic cities of Turkey. The theoretical approach of the paper is based on the transactional perspective, which considers home and home environments as a transactional whole that defines and is defined by a range of cultural, social and psychological factors. Observational and ethnographic research methods were used together with the detailed surveys throughout the empirical study.

\subsection{Description of the case study area}

Bursa is one of the valuable cities that could reach our times without losing its importance in Turkey (figure 1). It is the first capital of the Ottoman Empire and has always been an important focus point in social and historical aspects due to its location being suitable for settlement, natural structure's favouring agriculture and military strategic importance. Bursa is located in the centre of a plain with fertile land. However, as a result of it being a focus of large inner and outer immigration and undergoing a rapid process of industrialization, it has one of Turkey's highest population rate increases. This situation produces a demand on the fertile plain land and affects the development of the city [14]. Bursa, having an ancient and valuable past, faces urban problems of various aspects because of rapid development but promises a great future with very suitable features for the case study area in which, especially socio-cultural dimension of urban sustainability is examined within limits of traditional housing areas. These traditional zones, which are still being used as residential areas illustrate the characteristics of the compact city form with their mixed used building stock and transportation network. They are all in the centre of Bursa within walking distance to all of the public utilities and are connected to the newly developed parts of the city with public transport alternatives. They also have a congestion of facilities, traffic and urban land-use alternatives that don't exceed the carrying capacity of the city. Some views from these traditional neighbourhoods having different locations in the centre of the city are seen in figure 2.

The neighbourhood of "Hisar", the city's oldest place of settlement which includes traditional housing patterns preserved to the best level up until today, has been selected as a sample traditional settlement. Surrounded by the old city walls, the neighbourhood is located to the west of the centre on a hill overlooking the city (figure 3). Unfortunately, a wide motorway has been constructed in the neighbourhood of Hisar as a part of reconstruction and modernization works to 
64 The Sustainable City X



Figure 1: Location of Bursa in Turkey.
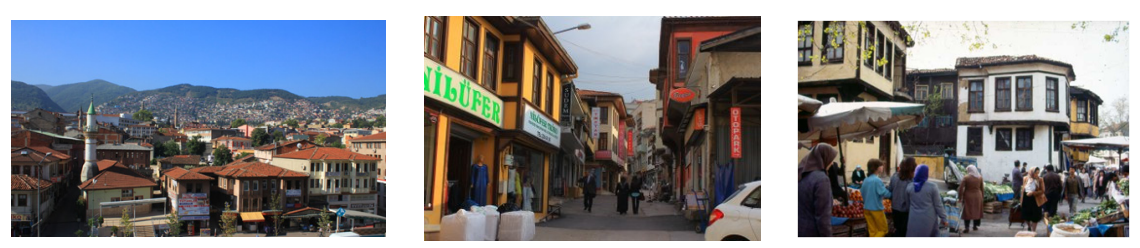

Figure 2: Views from Reyhan, Tuzpazarı and Muradiye neighbourhoods.

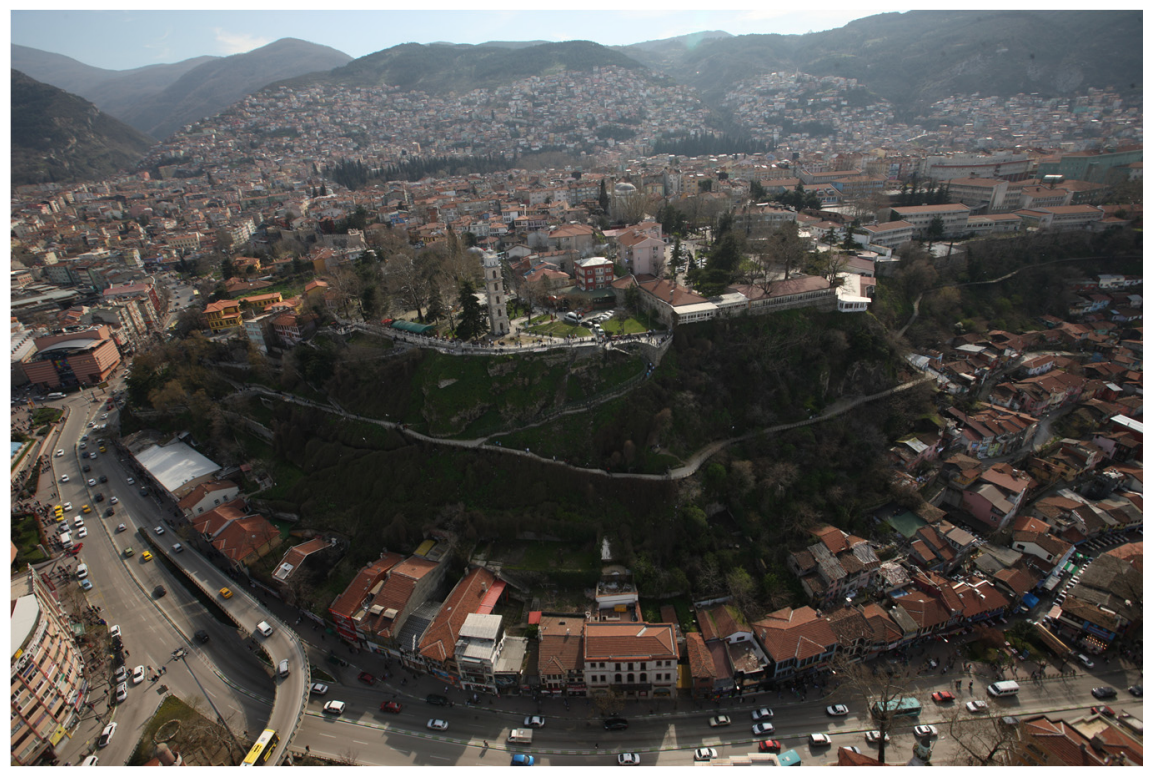

Figure 3: Location of Hisar in Bursa (from Metropolitan Municipality Archive). 
great extent. However, the urban fabric of Hisar, with its narrow roads and blind alleys and the morphological characteristics of its built environment, give it a special identity, very different to that of the other neighbourhoods (figure 4).

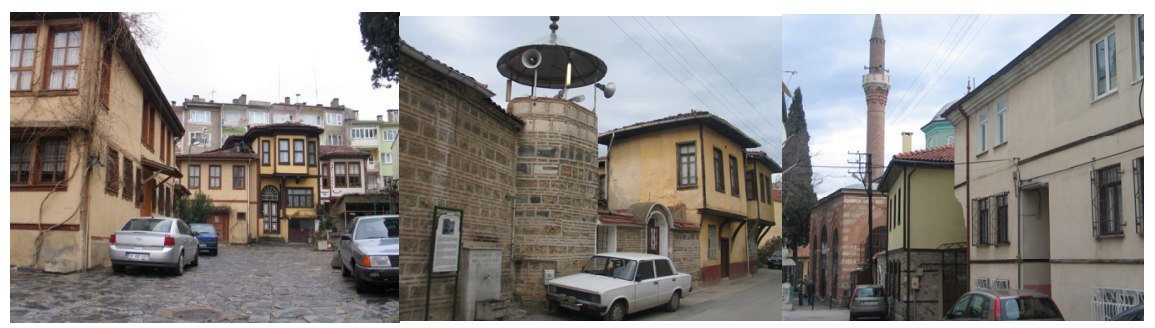

Figure 4: Views from "Hisar" (from Çahantimur's archive).

\subsection{The fieldwork}

The suitability of the compact city form for Hisar with its physical and social conditions, is evaluated in two steps. Firstly, making observations in the area and examining archival documents. Data relating to physical environment, history and social demography of the settlement have been obtained. The conclusions of these qualitative and quantitative environmental analyses are evaluated in order to understand if the environment is suitable for intensification that is vital for a compact city.

As a second step, the acceptance of the compact city form by the residents of the environment was examined with the help of a detailed survey. The questionnaire was composed of five main parts including questions in order to indicate the socio-cultural characteristics of the case study area, psychological characteristics of the case study area, physical requirements of sustainable urban development in the area, socio-cultural requirements of sustainable urban development in the area and alternative scenarios of the compact city form for the area respectively. The answers to the questions evaluating urban sustainability in terms of socio-cultural factors in the context of place identity, attachment and residential satisfaction and also evaluating the roles of user perception and participation for sustainable urban development of historic cities were critically important for the final results of the study.

These surveys were conducted to the people living both in traditional houses and also those living in newly constructed apartments in the same environment, half and half for the total number of survey. The ages and education levels of the interviewed people were important points in the evaluation of their answers. The questions were referred to the acceptance of the important changes, which will come out in the physical and socio-cultural qualities of the environment after an intensification process has been taken out in this environment. For example; the increase in the population and the number of cars, the changes in functions of some of the buildings, the new opportunities of work, the new places of social interaction, the alternative solutions for parking and traffic problems, etc. In the working out of data, statistical analysis method SPSS was applied. 


\subsection{Conclusions of the study}

As a result of archival data analysis and observations, physical, historical and socio-demographic data has been obtained regarding the area. Housing patterns of the Hisar area consist mostly of wooden houses bearing traditional Turkish features, narrow roads in the scale of human beings or blind alleys in some places, small squares with a small mosque or an awesome oriental plane tree in the centre. This structure contributes to the maintenance of social living. Residents of traditional houses mostly own their own homes, partly from being heirs to the previous owners, the other part are new owners, who have bought their houses sold due to lack of funds, restored them and moved in. Residents of apartment buildings in the same neighbourhood are mostly tenants, but some of them are owners. The residents are generally small size employers and employees who belong to the middle-income class. The area includes a lot of facilities and social opportunities due to its being within walking distance of the city centre. It was found that these physical, spatial and socio-cultural characteristics identified in the first study haven't changed since then.

As a result of the surveys conducted, it has been determined that most of the residents of traditional houses are absolutely satisfied by the location of their neighbourhood within the city, relations with their neighbours, social life and houses and that they would not prefer to reside in another neighbourhood or another house despite their houses' being underdeveloped due to lack of funds. It had been determined that the inhabitants of this traditional environment have powerful identity and attachment feelings, whether they live in a traditional house or in an apartment. It had also been determined that they are almost conscious about the cultural and historical values of their environment and agree to the idea of preservation and regeneration. In the first study, all of them were pessimistic about the future of their environment because of the uninterested authorities, however in the second study they indicated that municipality authorities have begun to do some restoration studies in and around the neighbourhood but they are insufficient in terms of both quantity and quality. Although most of them, especially the younger and well-educated group of the inhabitants, have knowledge about the meaning of the term sustainability, they don't exactly know how it can be provided. On the other hand, it is meaningful that local people are all ready to co-operate in anyway and want to help the authorities of the municipality for the benefit of their environment. The results of the surveys made in both of the studies show that the residents want their environment to be in better physical condition, especially the traditional houses. In the first study $83 \%$ and in the second one $85 \%$ of them, wanted the traditional houses to be restored or repaired and used more efficiently. However, they are not able to fund it and for this reason, they want the municipality to do something for their environment and they are ready to help in anyway.

All of these results show us that the residents of Hisar mostly accept the compact city form and its physical and socio-cultural needs as an alternative sustainable development form for their environment, because they feel that they belong to their neighbourhood and don't want to go anywhere else although most 
of them don't have a well-qualified house. The majority of them agree to the idea of restoration and repairing all of the houses and continue to use them efficiently. They accept the intensification of the area within the limits of its carrying capacity and want to benefit from this process especially by means of the socio-cultural and economic opportunities that will emerge. They were asked which out of three alternative scenarios of intensification they preferred; a compact residential area, a compact residential area together with the service and tourism functions for daytrips, a compact residential area together with touristic accommodation and the other service functions. In the first study the acceptance ratio of the first scenario was $82 \%$, the second scenario was $73 \%$ and the third scenario was $63 \%$. Surprisingly, six years after there were no meaningful changes and the acceptance ratio of the third scenario was again $63 \%$ although almost all of them want opportunities for work in one of the touristic facilities that will be proposed [15, $16]$.

\section{Final remarks}

As a result of the theoretical literature analysis made and of empirical studies carried out in this aspect, it has been justified that the compact city, which is one of the urban forms for sustainable development of cities is an appropriate one for sustainability of the historical neighbourhood Hisar in Bursa. The empirical studies made in the valuable traditional area of the city showed that by the opportunities of this urban form, it would be possible to accommodate substantial growth in the number of households without changing the original character of the environment and also to recreate a vital and viable city centre. It has been justified by the results of surveys that the idea of making people conscious about the concept of sustainability and adopt its requirements before any implementation of sustainability and taking their ideas about the future of their environment in the context of sustainable urban development would be a positive approach. This participative approach will be an important step towards providing social and psychological needs of sustainability besides the physical ones. We can conclude that this study can be an example for future studies to obtain sustainability in historic cities together with their residents.

\section{References}

[1] Short, J. R., The Urban Order, An Introduction to Cities, Culture and Power, pp. 173-207, Blackwell, USA,1996.

[2] Kleveland, A., Culture, Design and Democracy, Nyström, L., (ed.), City and Culture, Cultural Processes and Urban Sustainability, p. 60, Lenanders Tryckeri AB, Kalmar, 1999.

[3] Levine, et al., The Sustainable City of the 21st Century: Westbahnhof, Vienna - Theory and Practice, Kaiji, L, et al. (eds.), Architecture of the $21 \mathrm{st}$ Century, Vol. 1, pp. 68-69, 20th UIA Congress Book, Beijing, 1999. 
[4] Zeng Jian, et al., Opening a New Epoch of Architecture and Culture in the 21st Century, Kaiji, L., et al. (eds.), Architecture of the 21st Century, Vol. 1, 20th UIA Congress Book, Beijing, 1999.

[5] Breheny, M. (1996) 'Centrists, Decentrists and Compromisers: Views on the Future of Urban Form' in Jenks, M., Burton, E. and Williams, K. (eds.) The Compact City: a sustainable urban form? E\&FN Spon, London: pp. 13-35.

[6] URBED, Tomorrow: A Peaceful Path to Urban Reform, London: Friends of the Earth and Wise, 1998, from Heath, T., Achieving Sustainable Urban Form Through the Adaptive Re-use of Buildings For Residential Use, in Achieving Sustainable Urban Form, M. Jenks, K. Williams (eds.), E\&FN Spon, GB, 2000.

[7] Heath, T., Achieving Sustainable Urban Form Through the Adaptive Reuse of Buildings For Residential Use, in Achieving Sustainable Urban Form, M. Jenks, K. Williams (eds.), E\&FN Spon, GB, 2000.

[8] Elkin, T., et al., 1991, Reviving the City: Towards Sustainable Urban Development, Friends of the Earth, London, quoted from, Haughton, G. and Hunter, C., Sustainable Cities, Regional Policy and Development Series 7, pp. 15-20, 24-27, 40, Jessica Kingsley Pub., London, 1994.

[9] Haughton, G. and Hunter, C., Sustainable Cities, Regional Policy and Development Series 7, 311 pp., Jessica Kingsley Pub., London, 1994.

[10] Jenks, M., et al., Introduction, in The Compact City: A Successful, Desirable and Achievable Urban Form? Jenks, M., Burton, E., Williams, K., (eds.), E\&FN Spon, GB, 1996.

[11] Strange, I. Planning for Change, Conserving the Past: Towards Sustainable Development Policy in Historic Cities, Cities, Vol. 14(4), pp. 227-233, Elsevier Science Ltd., 1997.

[12] Strange, I., Urban Sustainability, Globalisation and the Pursuit of the Heritage Aesthetics, Planning Practice and Research, Vol. 14(3), p. 301, 1999.

[13] Altman, I., Foreword, Homes, Housing, and the 21st Century: Prospects and Challenges, Arias, E., (ed.), The Meaning and Use of Housing, Hants, Avebury, England, 1993.

[14] Çahantimur, A.I., The Impact of Different Urban Housing Patterns on the Sustainable Urban Development of a Historic City, Bursa/Turkey, Urban Development, Dr. Serafeim Polyzos (Ed.), ISBN: 978-953-51-0442-1, InTech, DOI: 10.5772/35968, 2012.

[15] Çahantimur, A.I., "A Socio-Cultural Approach for Sustainable Urban Development, A Case Study for Bursa", Ph.D. Thesis, in Institute of Science and Technology, Department of Architecture, ITU, Istanbul, 2007.

[16] Çahantimur, A.I.,"A Proposal of Site Management Plan for Hisar, Osmangazi/Bursa", unpublished scientific research project carried out by the first author within the collaboration of Uludağ University and Bursa Metropolitan Municipality with the number, M.16.0.BBB.0.31.53.604.99138597, Bursa, 2013. 